\title{
Luminescence of Vanadium and Rare Earth Ions in Alkaline Earth Sulfates
}

\author{
G. BLASSE AND H. G. PIETERSEN \\ Solid State Department, Physical Laboratory, State University, Utrecht, The \\ Netherlands
}

Received December 18, 1973

\begin{abstract}
The luminescence of samples $\mathrm{MeSO}_{4}-\mathrm{V}, \mathrm{RE}(\mathrm{Me}=\mathrm{Mg}, \mathrm{Ca}, \mathrm{Ba})$ depends strongly on the nature of the Me ions. The amount of association of the $\mathrm{V}^{5+}$ and $\mathrm{RE}^{3+}$ ions can be estimated from the measured quantum efficiencies.
\end{abstract}

Recently the luminescence of vanadium and rare earth (RE) ions in calcium sulfate has been investigated in this laboratory $(1,2)$. It appeared that $\mathrm{V}^{5+}$ and $\mathrm{RE}^{3+}$ ions in $\mathrm{CaSO}_{4}$ occur as associates in which the energy transfer from the vanadate group to the $\mathrm{RE}^{3+}$ ions could be studied. Among others it was found for the first time that efficient energy transfer from the vanadate group to the $\mathrm{Tb}^{3+}$ ion occurs.

In this note we report a similar investigation in 2 other host lattices, viz $\mathrm{MgSO}_{4}$ and $\mathrm{BaSO}_{4}$. The $\mathrm{Mg}^{2+}$ ion is smaller than the $\mathrm{Ca}^{2+}$ ion, the $\mathrm{Ba}^{2+}$ ion is larger. The experimental conditions were the same as described before $(1,2)$. Sample compositions were either $\mathrm{MS}_{0.999} \mathrm{~V}_{0.001} \mathrm{O}_{4}$ or $\mathrm{M}_{0.999} \mathrm{RE}_{0.001} \mathrm{~S}_{0.999} \mathrm{~V}_{0.001}$ $\mathrm{O}_{4}(\mathrm{M}=\mathrm{Mg}$ or $\mathrm{Ba})$.

The luminescence of the $\mathrm{BaSO}_{4}$ samples was weak at room temperature and at liquid nitrogen temperature except for the blue emission of $\mathrm{BaSO}_{4}-\mathrm{V}, \mathrm{Y}$ (with quenching temperature, $T_{a}$, about $150^{\circ} \mathrm{K}$ ) and the yellow emission of $\mathrm{BaSO}_{4}-\mathrm{V}$ (with $T_{q}$ about $80^{\circ} \mathrm{K}$ ). In comparison with the $\mathrm{CaSO}_{4}$ samples $(1,2)$ the intensities and $T_{q}$ are considerably lower. The $\mathrm{MgSO}_{4}$ samples show much higher intensities and $T_{q}$ than $\mathrm{CaSO}_{4}$ and $\mathrm{BaSO}_{4}$ samples and were, therefore, investigated in more detail. $\mathrm{MgSO}_{4}-\mathrm{V}$ as well as $\mathrm{MgSO}_{4}-$ $\mathrm{V}, \mathrm{Y}$ show a yellow emission under shortwave ultraviolet excitation with $T_{q}$ about $400^{\circ} \mathrm{K}$.

Copyright (C) 1974 by Academic Press, Inc.

All rights of reproduction in any form reserved. Printed in Great Britain

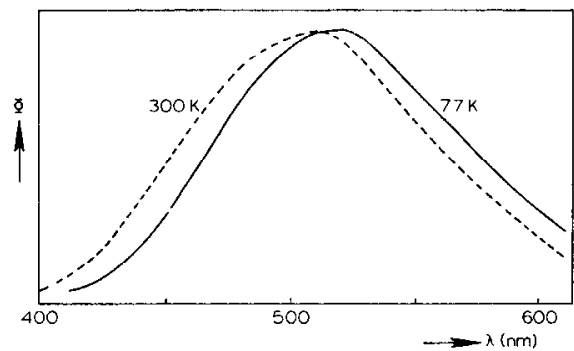

FIG. 1. Spectral energy distribution of the emission of $\mathrm{Mg}_{0.999} \mathrm{Y}_{0.001} \mathrm{~S}_{0.999} \mathrm{~V}_{0.001} \mathrm{O}_{4}$ at 77 and $300^{\circ} \mathrm{K}$ for $240 \mathrm{~nm}$ excitation. $\Phi$ is the spectral radiant power in arbitrary units.

The intensity of the luminescence increases, if the sample temperature is lowered from room to liquid nitrogen temperature. The spectral energy distribution of this yellow emission is slightly dependent on sample temperature and excitation wavelength. Figure 1 shows the emission spectra of $\mathrm{MgSO}_{4}-\mathrm{V}, \mathrm{Y}$ at 300 and $77^{\circ} \mathrm{K}$. Replotted on an energy scale these emission curves are fairly symmetrical with half width about $4.500 \mathrm{~cm}^{-1}$. In the case of $\mathrm{CaSO}_{4}$ this value is about $5.500 \mathrm{~cm}^{-1}$.

Samples $\mathrm{MgSO}_{4}-\mathrm{V}, \mathrm{RE}(\mathrm{RE}=\mathrm{Sm}, \mathrm{Tb}, \mathrm{Dy})$ show vanadate as well as characteristic rare earth emission upon excitation into the strong absorption band of the vanadate group, which peaks at about $250 \mathrm{~nm}$. This is different from the analogous $\mathrm{CaSO}_{4}$ samples where only rare earth emission is observed. Table 
TABLE I

Ratio OF THE QUANTUM EFFICIENCY OF THE $\mathrm{RE}^{3+}$ EMISSION AND THE TOTAL Quantum EFFICIENCY OF SAMPles $\mathrm{Mg}_{0.999} \mathrm{RE}_{0.001} \mathrm{~S}_{0.999} \mathrm{~V}_{0.001} \mathrm{O}_{4}$ AT $77^{\circ} \mathrm{K}$ FOR EXCITATION INTO THE VANADATE Group (THE IONIC Radius of $\mathrm{RE}^{3+}$ (ACCORDING TO ReF. 4) is ALSO GIVEN)

\begin{tabular}{llll}
\hline & $\mathrm{Dy}^{3+}$ & $\mathrm{Tb}^{3+}$ & $\mathrm{Sm}^{3+}$ \\
$q_{\mathrm{RE}^{3+}}$ & 0.3 & $0.2^{5}$ & $0.1^{5}$ \\
$q_{\mathrm{tota1}}$ & 0.91 & 0.92 & 0.96 \\
\hline
\end{tabular}

I gives the ratio between the quanta emitted by the rare earth ions in $\mathrm{MgSO}_{4}-\mathrm{V}, \mathrm{RE}$ and the total number of quanta emitted after excitation into the vanadate group at $77^{\circ} \mathrm{K}$.

From these results the following conclusions may be drawn.

$a$. The quenching temperature of the vanadate emission in the different sulfates behaves as expected from the model given before $(1,2)$. Figure 2 gives a survey of the values of $T_{q}$ plotted as a function of the ionic radius of the alkaline earth ion in the host lattice. Note that $T_{q}$ decreases, if this ionic radius increases. A small ionic radius gives a stiff host lattice and, therefore, a high value of $T_{4}$. Note also that the variation of $T_{a}$ is different for $\mathrm{MSO}_{4}-\mathrm{V}$ and $\mathrm{MSO}_{4}-\mathrm{V}, \mathrm{Y}$. This indicates that

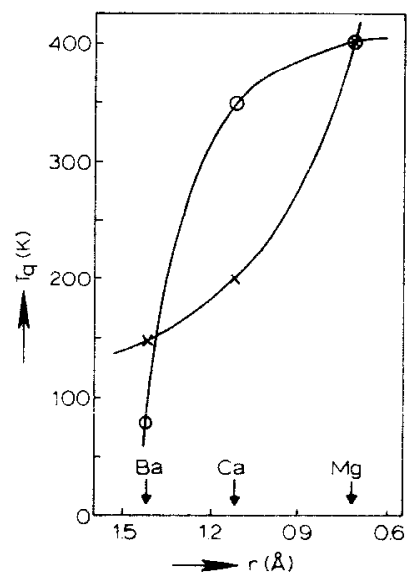

FIG. 2. Quenching temperature $T_{q}$ of the vanadate emission of $\mathrm{MS}_{0.999} \mathrm{~V}_{0.001} \mathrm{O}_{4}$ (circles) and $\mathrm{M}_{0.999}$ $\mathrm{Y}_{0.001} \mathrm{~S}_{0.999} \mathrm{~V}_{0.001} \mathrm{O}_{4}$ (crosses) as a function of the ionic radius of $\mathrm{M}^{2+}$ (according to Ref. 4). the luminescent centres involved are indeed different. For $\mathrm{MSO}_{4}-\mathrm{V}, \mathrm{Y}$ only the regular host lattice ions vary. For $\mathrm{MSO}_{4}-\mathrm{V}$ the nature of the compensating defect may also vary. If this would be an interstitial alkaline earth ion as supposed in Ref. 2 it is immediately clear that the nature of the compensating defect varies also. These results agree with the observation made by Kotera et al. (3) that vanadium ions luminesce in $\mathrm{MgSO}_{4}$ at room temperature but not so in $\mathrm{BaSO}_{4}$.

$b$. From the present data we can estimate the amount of association of $\mathrm{V}^{5+}$ and $\mathrm{RE}^{3+}$ in $\mathrm{MgSO}_{4}$. In $\mathrm{CaSO}_{4}$ this is very near to $100 \%$. Since energy transfer from the vanadate group to $\mathrm{RE}^{3+}$ ions is restricted to nearest neighbours, i.e., associated vanadate groups do not luminesce, but transfer their excitation energy to the near $\mathrm{RE}^{3+}$ ion, whereas unassociated vanadate groups emit their own luminescence, the amount of association in $\mathrm{MgSO}_{4}$ at a $\mathrm{V}$ and RE concentration of $0.1 \%$ is about $20 \%$ (see Table I). It tends to be lower for larger $\mathrm{RE}^{3+}$ ions and higher for smaller $\mathrm{RE}^{3+}$ ions. The fact that association is incomplete in $\mathrm{MgSO}_{4}$ in contradistinction to $\mathrm{CaSO}_{4}$ may be due to the fact that in $\mathrm{MgSO}_{4}$ the $\mathrm{V}^{5+}$ and $\mathrm{RE}^{3+}$ ions are considerably larger than the host lattice ions (ionic radic $\mathrm{V}^{5+} 0.35 \AA, \mathrm{S}^{6+} 0.12 \AA, \mathrm{RE}^{3+}$ 0.9-1.0 $\left.\AA, \mathrm{Mg}^{2+} 0.72 \AA(4)\right)$, whereas in $\mathrm{CaSO}_{4}$ the $\mathrm{RE}^{3+}$ ions fit into the $\mathrm{Ca}^{2+}$ sites $\left(\mathrm{Ca}^{2+}\right.$ $1.12 \AA$ ). The association of 2 too large ions is probably unfavourable. The fact that the amount of association tends to be lower for larger $\mathrm{RE}^{3+}$ ions agrees with this assumption.

c. Also in $\mathrm{MgSO}_{4}$ energy transfer from the vanadate group to the $\mathrm{Tb}^{3+}$ ion occurs.

$d$. The slight dependence of the vanadate emission spectra upon excitation wavelength may be due to the presence of crystallographically different $\mathrm{V}^{5+}$ ions as argued in Ref. 2.

\section{References}

1. W. HoRdiJK AND G. BLASSE, J. Luminescence 6, 137 (1973).

2. W. T. Draai and G. Blasse, Phys. Status Solidi, (a) 21, 569 (1974); (b) Chem. Phys. Lett. 25, 167 (1974).

3. Y. Kotera, M. Yonemura, and T. Sekine, $J$. Electrochem. Soc. 108, 540 (1961).

4. R. D. Shannon and C. T. Prewitr, Acta Cryst. B25, 925 (1969). 